\title{
Intensitas dan Luas Serangan Beberapa Isolat Fusarium oxysporum f.sp. zingiberi pada Jahe Gajah
}

\author{
The Disease Intensity and Level of Attack of Fusarium oxysporum f.sp. zingiberi \\ on Ginger
}

\author{
Hermawati Cahyaningrum $^{1) *}$, Nur Prihatiningsih ${ }^{2)}, \&$ Soedarmono $^{2)}$ \\ 1)Balai Pengkajian Teknologi Pertanian Maluku Utara \\ Kompleks Pertanian Kusu No. 1, Oba Utara, Kota Tidore Kepulauan 97717 \\ 2) Jurusan Hama Penyakit Tumbuhan, Fakultas Pertanian, Universitas Jenderal Soedirman \\ Kompleks Fakultas Pertanian UNSOED, Jln. Dr. Suparno Kotak Pos 125, Purwokerto 53123 \\ *Penulis untuk korespondesi.E-mail: herma.cahyaningrum@gmail.com
}

Diterima 18 Juli 2016; diterima untuk diterbitkan 4 Januari 2017

\begin{abstract}
Ginger is one of the spices and medicinal commodities which is cultivated in Indonesia. One of the obstacles encountered in the cultivation of ginger is the rhizome rot disease which is mainly caused by Fusarium oxysporum Schlecht f.sp. zingiberi Trujillo. This study is aimed to know the growth ability and virulence level of the isolates on ginger rhizome and plants. The research was conducted in the laboratory and in the screen house by using Complete Random Design consisted of 10 treatments and 4 replications. The parameters observed were growth ability of $\mathrm{F}$. oxysporum $f$.sp. zingiberi, rhizome rot disease symptoms, incubation period, extensive decay and weight difference of the rhizomes. The results showed that $\mathrm{F}$. oxysporum $f . s p$. zingiberi which was stored for 4 years in sterile soil medium was still capable to cause damage to the rhizome and plants. Incubation periods of rhizome decay and plant symptoms were from 3 to 11.5 and 55.5 to 68.5 days, respectively. The most virulent isolate was MSO1 with extensive decay of rhizome and the wilting intensity were $108.95 \mathrm{~mm}^{2}$ dan $33.88 \%$, respectively.
\end{abstract}

Keywords: disease intensity, Fusarium oxysporum f.sp. zingiberi, ginger rhizome rot, virulence

\section{INTISARI}

Jahe merupakan salah satu komoditas rempah dan obat yang banyak dibudidayakan di Indonesia. Salah satu kendala yang dihadapi dalam budidaya jahe adalah adanya gangguan penyakit busuk rimpang yang disebabkan (terutama) oleh Fusarium oxysporum Schlecht f.sp. zingiberi Trujillo. Penelitian bertujuan untuk menguji daya tumbuh dan virulensi isolat $F$. oxysporum f.sp. zingiberi pada rimpang dan tanaman jahe gajah. Penelitian dilakukan di laboratorium dan di rumah kasa menggunakan Rancangan Acak Kelompok Lengkap (RAKL) yang masing-masing terdiri dari 10 perlakuan dan 4 ulangan. Parameter yang diamati meliputi daya tumbuh $F$. oxysporum f.sp. zingiberi, gejala penyakit busuk rimpang, masa inkubasi, luas pembusukan dan selisih bobot basah rimpang. Hasil penelitian menunjukkan bahwa $F$. oxysporum f.sp. zingiberi yang telah di simpan 4 tahun dalam medium tanah steril mampu menyebabkan kerusakan pada rimpang dan tanaman jahe. Masa inkubasi gejala busuk pada rimpang serta gejala pada tanaman masing- masing berkisar antara 3-11,5 serta 55,5-68,5 hari. Isolat yang paling virulen adalah MSO1 dengan nilai luas pembusukan pada rimpang dan intensitas penyakit masing-masing sebesar $108,95 \mathrm{~mm}^{2}$ dan $33,88 \%$.

Kata kunci: busuk rimpang jahe, Fusarium oxysporum f.sp. zingiberi, intensitas penyakit, virulensi

\section{PENGANTAR}

Jahe (Zingiber officinale Rosc.) merupakan salah satu komoditas tanaman rempah dan obat yang banyak dikembangkan di berbagai daerah karena banyak kegunaannya. Selain sebagai bumbu, bahan obat tradisional, manisan, atau minuman penyegar, jahe juga merupakan bahan komoditas andalan untuk ekspor nonmigas (Rukmana, 2000). Produksi jahe mengalami peningkatan setiap tahun, di Indonesia produksinya mengalami kenaikan dari tahun 2003-2007 yaitu sebesar 125.389.480; 104.788.634; 125.827.413; 177.137.949; dan 178.502.542 kg (Anonim, 2010).

Penyakit busuk rimpang yang disebabkan oleh jamur Fusarium oxysporum Schlecht f.sp. zingiberi Trujillo merupakan salah satu kendala utama dalam budidaya jahe (Semangun, 2000). Patogen ini banyak 
ditemukan pada tanaman jahe di delapan kabupaten di provinsi Jawa Tengah yaitu: Karanganyar, Boyolali, Temanggung, Salatiga, Magelang, Purworejo, Banyumas, dan Purbalingga (Soesanto et al., 2002). Beberapa isolat $F$. oxysporum f.sp. zingiberi dari masing-masing kabupaten sampel digunakan dalam penelitian lanjutan.

F. oxysporum dilaporkan sebagai penyebab penyakit pada tanaman pertanian dan mempunyai penyebaran yang sangat luas karena klamidospora relatif tahan terhadap lingkungan kritis (Tombe et al., 1997). Jamur mampu bertahan hidup di dalam tanah dalam bentuk miselium, mikrokonidium, makrokonidium, atau klamidospora (Agrios, 1988). Soesanto (2006) menyatakan bahwa jamur Fusarium sp. mampu bertahan hidup di dalam tanah dalam jangka waktu lama, bahkan dalam keadaan tanpa adanya tanaman inang. Penelitian bertujuan untuk menguji daya tumbuh, virulensi isolat dan gejala $F$. oxysporum f.sp. zingiberi. Informasi tentang perkembangan penyakit busuk rimpang jahe dan virulensi $F$. oxysporum $\mathrm{f}$ sp. zingiberi pada tanaman jahe diharapkan dapat digunakan sebagai bahan pertimbangan dalam melakukan tindakan pengendalian di lapangan.

\section{BAHAN DAN METODE}

Penelitian dilaksanakan dalam dua tahap yaitu penelitian in vitro dan in vivo dengan masing-masing 10 perlakuan dan tiap perlakuan diulang sebanyak 4 kali. Parameter yang diamati meliputi daya tumbuh F. oxysporum f.sp. zingiberi, gejala penyakit busuk rimpang, masa inkubasi, luas pembusukan dan selisih bobot basah rimpang.

Bibit jahe diperoleh dari pengepul jahe dan berasal dari Kroya, Jawa Tengah. Bibit yang dipilih adalah bibit jahe yang sehat dengan ciri kulit bibit tidak lerluka dan lecet, bibit kemudian disemai dalam tumpukan kertas lembap sampai keluar tunasnya selama kurang lebih 15 hari. Isolat F.oxysporum f.sp. zingiberi yang digunakan adalah isolat TKO2 sebagai kontrol positif, MSO1, MSO2, MBO3, PBO5, PKO3, SAO1, SAO3, SAO6. Semua isolat diperoleh dari koleksi Laboratorium Penyakit Tumbuhan Fakultas Pertanian Universitas Jenderal Soedirman, Purwokerto.

Perbanyakan F. oxysporum f.sp. zingiberi dilakukan dengan melakukan isolasi spora tunggal. Tanah steril yang mengandung jamur ditumbuhkan pada medium PDA dan diinkubasikan selama 5 hari. Miselium yang tumbuh dilarutkan dalam air steril pada tabung reaksi menggunakan vortex sampai larut.
Isolasi $F$. oxysporum f.sp. zingiberi dilakukan dengan mengambil suspensi jamur dengan menggunakan pipet steril sebanyak satu tetes kemudian ditumbuhkan pada medium agar air dan diinkubasikan selama kurang lebih 15 jam. Pengamatan spora tunggal dilakukan dengan menggunakan mikroskop. Spora tunggal yang tumbuh pada medium agar air, diambil kemudian dipindahkan pada medium PDA dan diinkubasi sampai miselium tumbuh.

Perbanyakan isolat dilakukan dengan menumbuhkan jamur pada medium PDA yang telah dicampur dengan streptomycin sebanyak $0,125 \mathrm{~g} / 1$ kemudian diinkubasikan selama 5 hari.

Rimpang jahe yang akan diperlakukan, disterilkan terlebih dahulu dengan cara merendam rimpang ke dalam larutan Na-hipoklorit 1\% selama kurang lebih 3 menit kemudian dibilas dengan air steril. Luka tusukan dibuat dengan menggunakan jarum preparat steril dengan kedalaman kurang lebih $0,5 \mathrm{~mm}$ dan luas $0,5 \mathrm{~cm}^{2}$. Suspensi konidium jamur $F$. oxysporum f.sp. zingiberi dengan kerapatan $10^{7}$ diinokulasikan sebanyak 1 tetes pada rimpang jahe yang telah dilukai kemudian ditutup dengan kapas lembab, dimasukkan ke dalam kantong plastik dan diinkubasi dalam suhu kamar $\left(25^{\circ} \mathrm{C}\right)$.

Penelitian in vivo dilaksanakan di rumah kasa menggunakan rancangan acak kelompok lengkap. Peubah yang diamati yaitu gejala penyakit busuk rimpang, masa inkubasi, intensitas penyakit, tinggi tanaman, jumlah daun dengan peubah pendukung suhu dan kelembapan tanah.

Media tanam jahe berupa tanah yang dicampur pupuk kandang $(3: 1)$ yang telah disterilkan terlebih dahulu kemudian dimasukkan dalam polibag berkapasitas $3 \mathrm{~kg}$. Suspensi konidium F. oxysporum f.sp. zingiberi dengan kerapatan masing-masing $10^{7}$ konidium per $\mathrm{ml}$ suspensi disiramkan ke media tanam sebanyak $10 \mathrm{ml}$ per polibag. Bibit jahe kemudian ditanam, masing-masing polibag ditanami 3 bibit. Tanaman dipelihara selama 3 bulan.

Masa inkubasi dihitung sejak inokulasi sampai muncul gejala dalam satuan hari setelah inokulasi (hsi). Gejala penyakit busuk rimpang diamati setiap minggu sekali bersama-sama dengan pengamatan intensitas penyakit busuk rimpang. Intensitas penyakit busuk rimpang jahe dihitung dengan rumus:

$$
\mathrm{IP}=\frac{\sum(\mathrm{n} \times \mathrm{v})}{\mathrm{N} \times \mathrm{Z}} \times 100 \%
$$


di mana IP = Intensitas Penyakit, $\mathrm{n}=$ Jumlah daun yang terinfeksi pada tiap kategori, $\mathrm{v}=$ Nilai numerik dari tiap kategori serangan, $\mathrm{Z}=$ Nilai numerik kategori tertinggi, $\mathrm{N}=$ Jumlah seluruh daun yang diamati. Kategori serangan patogen busuk rimpang didasarkan luas serangan pada daun: $0=$ jika $0 \%$ daun menguning, $1=$ jika $>0-10 \%$ daun menguning, $2=$ jika $>10-30 \%$ daun menguning, $3=$ jika $>30-50 \%$ daun menguning, $4=$ jika $>50-70 \%$ daun menguning, $5=$ jika $>70-100 \%$ daun menguning (Amalia, 2004). Tinggi tanaman diamati sejak 1 minggu setelah tumbuh tunas setiap 1 minggu sekali, diukur dari permukaan tanah sampai titik tumbuh tertinggi dalam $\mathrm{cm}$. Jumlah daun dihitung sebelum masa panen yaitu di akhir pengamatan. Kelembapan tanah dan $\mathrm{pH}$ diukur menggunakan soil tester, suhu tanah diukur dengan termometer tanah.

Data dianalisis dengan menggunakan analisis ragam. Sebelum dianalisis, data masa inkubasi dan data luas serangan ditransformasi dan intensitas penyakit ditransformasi ke arc sin. Apabila terdapat beda nyata dilanjutkan dengan Uji Jarak Berganda Duncan (UJBD) pada taraf kesalahan 5\%.

\section{HASIL DAN PEMBAHASAN}

\section{Penelitian In vitro}

Jamur $F$. oxysporum f.sp. zingiberi yang telah disimpan selama 4 tahun pada medium tanah steril ternyata masih dapat tumbuh dengan baik pada medium PDA (Gambar 1a). Rimpang jahe yang diperlakukan menunjukkan keriput, cekung yang semakin lama semakin lebar dan dalam dan terjadi busuk kering (Gambar 1b). Soesanto et al. (2002) menemukan bahwa gejala yang tampak dari penyakit busuk rimpang yang disebabkan oleh $F$. oxysporum f.sp. zingiberii adalah bentuk rimpang yang berubah menjadi keriput, berwarna keputihan, dan mengering. Hal ini menunjukkan bahwa masing-masing isolat yang telah disimpan selama kurang lebih 4 tahun dalam medium tanah steril masih mampu menimbulkan gejala pada rimpang melalui luka. Semangun (2000) menyatakan bahwa patogen memanfaatkan akar atau rimpang yang mengalami pelukaan sebagai jalan masuk ke dalam jaringan inang.

Rerata masa inkubasi, luas serangan, dan selisih bobot basah rimpang tertera pada Tabel 1 . Hasil analisis statistika menunjukkan bahwa pada masa inkubasi, luas serangan dan selisih bobot basah rimpang tidak terdapat perbedaan nyata di antara perlakuan yang diuji.

Masa inkubasi penyakit busuk rimpang adalah 2-4 hari (Pancasiwi, 2004). Pada penelitian ini, masa inkubasi penyakit busuk rimpang pada rimpang jahe adalah 3-11,5 hari (Tabel 1). Adanya perbedaan ini menunjukkan bahwa kemampuan patogen dalam melakukan proses infeksi telah mengalami penurunan. Penurunan virulensi ini terjadi karena isolat yang digunakan telah lama disimpan dalam medium tanah steril, sesuai dengan pendapat Agrios (1988)

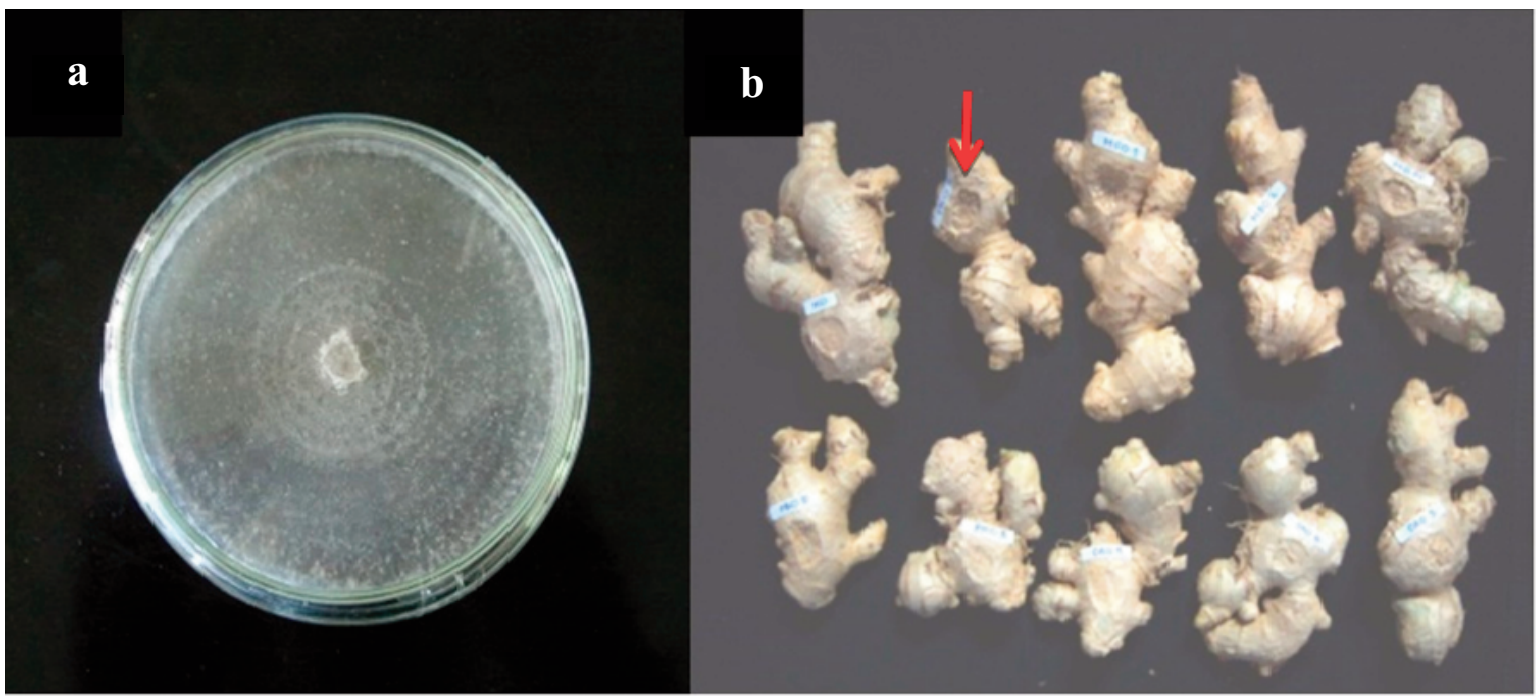

Gambar 1. Pertumbuhan F. oxysporum f. sp. zingiberi umur 7 hari pada medium PDA (a); gejala pada rimpang (tanda panah merah) berupa rimpang yang keriput, cekung dan terjadi busuk kering (b) 
Tabel 1. Masa inkubasi, luas serangan Fusarium oxysporum f.sp. zingiberi pada rimpang jahe dan selisih bobot basah rimpang jahe

\begin{tabular}{lrcc}
\hline Isolat & Masa Inkubasi (hsi) & Luas Serangan $(\mathrm{mm} 2)$ & Selisih Bobot Basah Rimpang (gram) \\
\hline KO & $21,00 \mathrm{a}$ & $20,85 \mathrm{a}$ & $0,46 \mathrm{a}$ \\
TKO2 & $12,75 \mathrm{a}$ & $37,10 \mathrm{a}$ & $0,83 \mathrm{a}$ \\
MSO1 & $3,25 \mathrm{a}$ & $108,95 \mathrm{a}$ & $3,14 \mathrm{a}$ \\
MBO2 & $5,50 \mathrm{a}$ & $94,55 \mathrm{a}$ & $1,91 \mathrm{a}$ \\
MBM & $8,75 \mathrm{a}$ & $80,65 \mathrm{a}$ & $1,59 \mathrm{a}$ \\
PBO5 & $6,00 \mathrm{a}$ & $108,75 \mathrm{a}$ & $2,34 \mathrm{a}$ \\
PKO3 & $9,75 \mathrm{a}$ & $62,90 \mathrm{a}$ & $1,55 \mathrm{a}$ \\
SAO1 & $8,50 \mathrm{a}$ & $72,10 \mathrm{a}$ & $1,72 \mathrm{a}$ \\
SAO3 & $11,50 \mathrm{a}$ & $57,45 \mathrm{a}$ & $0,83 \mathrm{a}$ \\
SAO6 & $10,00 \mathrm{a}$ & $66,90 \mathrm{a}$ & $1,15 \mathrm{a}$ \\
\hline
\end{tabular}

Keterangan: Angka yang diikuti dengan huruf yang sama pada kolom yang sama tidak berbeda nyata menurut UJBD pada taraf kesalahan 5\%.

Tabel 2. Masa inkubasi, intensitas penyakit busuk rimpang pada tanaman jahe, tinggi tanaman, dan jumlah daun jahe

\begin{tabular}{ccccc}
\hline Isolat & Masa Inkubasi (hsi) & Intensitas Penyakit (\%) & Tinggi Tanaman $(\mathrm{cm})$ & Jumlah Daun (helai) \\
\hline KO & $68,50 \mathrm{~d}$ & $20,14 \mathrm{a}$ & $21,42 \mathrm{a}$ & $16,26 \mathrm{a}$ \\
TKO2 & $61,30 \mathrm{bc}$ & $26,37 \mathrm{a}$ & $26,57 \mathrm{a}$ & $18,15 \mathrm{a}$ \\
MSO1 & $55,50 \mathrm{a}$ & $33,88 \mathrm{a}$ & $26,36 \mathrm{a}$ & $14,52 \mathrm{a}$ \\
MBO2 & $57,50 \mathrm{ab}$ & $31,38 \mathrm{a}$ & $29,46 \mathrm{a}$ & $20,66 \mathrm{a}$ \\
MBM & $56,30 \mathrm{a}$ & $21,94 \mathrm{a}$ & $30,30 \mathrm{a}$ & $21,07 \mathrm{a}$ \\
PBO5 & $57,50 \mathrm{ab}$ & $24,40 \mathrm{a}$ & $26,98 \mathrm{a}$ & $18,09 \mathrm{a}$ \\
PKO3 & $66,80 \mathrm{~d}$ & $31,05 \mathrm{a}$ & $23,03 \mathrm{a}$ & $20,90 \mathrm{a}$ \\
SAO1 & $56,30 \mathrm{a}$ & $21,12 \mathrm{a}$ & $23,64 \mathrm{a}$ & $20,79 \mathrm{a}$ \\
SAO3 & $65,00 \mathrm{~cd}$ & $26,81 \mathrm{a}$ & $26,87 \mathrm{a}$ & $19,57 \mathrm{a}$ \\
SAO6 & $65,50 \mathrm{~cd}$ & $22,27 \mathrm{a}$ & $16,48 \mathrm{a}$ & $9,68 \mathrm{a}$ \\
\hline
\end{tabular}

Keterangan: Angka yang diikuti dengan huruf yang sama pada kolom yang sama tidak berbeda nyata menurut UJBD pada taraf kesalahan $5 \%$.

yang menyatakan virulensi mikroba patogen terhadap satu atau semua inangnya akan mengalami penurunan apabila patogen tersebut tetap dipelihara dalam biakan dalam jangka waktu yang cukup lama. Meskipun menurut Salleh cit. Soesanto (2006) penyimpanan isolat jamur Fusarium sp. memungkinkan dapat tetap hidup lebih dari 10 tahun. Rerata masa inkubasi tercepat terdapat pada isolat MSO1 dan masa inkubasi terlama pada isolat SAO3 (Tabel 1). Walaupun terdapat perbedaan masa inkubasi ini, setelah penyimpanan pada medium steril, semua isolat dapat tumbuh pada medium agar kentang.

Hasil analisis statistika terhadap luas serangan menunjukkan bahwa masing-masing perlakuan tidak berbeda nyata, sehingga dapat dikatakan bahwa kemampuan patogen dalam menimbulkan gejala pada rimpang jahe adalah sama. Meskipun demikian, rerata luas serangan terbesar ditunjukkan oleh isolat MSO1 yaitu dan terendah pada SAO3 (Tabel 1).
Penyakit busuk rimpang pada tanaman jahe yang disebabkan oleh $F$. oxysporum f.sp. zingiberi menyebabkan rimpang mengerut dan berkeriput yang dapat mengakibatkan terjadinya penurunan bobot rimpang basah serta morfologi rimpang (Semangun, 2000). Hasil analisis statistika terhadap selisih bobot basah rimpang menunjukkan bahwa pada masingmasing perlakuan yang diuji tidak berbeda nyata. Pada semua perlakuan menunjukkan terjadinya penurunan bobot basah rimpang. Rerata selisih bobot tertinggi ditunjukkan oleh isolat $\mathrm{MBO} 2$ dan yang paling rendah adalah SAO3 (Tabel 1). Keragaman nilai selisih bobot tersebut diduga berkaitan dengan masa inkubasi dan luas serangan yang tidak berbeda nyata berdasarkan dari hasil analisis statistika. Isolat yang memiliki masa inkubasi tercepat dan memiliki luas serangan terbesar (MSO1) menyebabkan susut bobot yang paling besar pula. Lamanya masa inkubasi memengaruhi perkembangan patogen dalam menyebabkan kerusakan pada rimpang jahe. 


\section{Penelitian In vivo}

Rerata masa inkubasi penyakit busuk rimpang, intensitas penyakit, tinggi tanaman jahe, dan jumlah daun dapat dilihat pada Tabel 2. Hasil analisis statistika terhadap masa inkubasi menunjukkan terdapat perbedaan nyata pada masing-masing perlakuan, tetapi pada nilai intensitas penyakit, tinggi tanaman, dan jumlah daun menunjukkan tidak ada perbedaan.

\section{Masa Inkubasi dan Gejala Penyakit}

Berdasarkan hasil analisis statistika, terdapat perbedaan yang nyata di antara perlakuan. Kisaran nilai rerata masa inkubasi penyakit busuk rimpang pada tanaman jahe adalah 55,50-68,50 hsi (Tabel. 2). Perlakuan yang tercepat menunjukkan gejala penyakit adalah isolat MSO1 dan masa inkubasi terlama terlihat pada isolat PKO3. Apabila dibandingkan dengan penelitian Pancasiwi (2004), masa inkubasi tanaman jahe gajah sekitar 51 hsi maka tidak jauh berbeda. Namun, apabila dibandingkan dengan penelitian Winarni (2004), inkubasi tanaman jahe gajah antara 26-30,67 hsi maka terdapat perbedaan yang cukup jauh. Hal ini diduga pada masing-masing isolat $F$. oxysporum f.sp. zingiberi mengalami penurunan virulensi.

Berdasarkan pada penelitian in vitro, tidak semua isolat menunjukkan masa inkubasi yang sama. Isolat MSO1 merupakan isolat yang memiliki masa inkubasi tercepat baik di laboratorium maupun di rumah kasa. Akan tetapi, masa inkubasi isolat PKO3 tidak sama antara di laboratorium dan di rumah kasa, hal ini diduga terjadi karena adanya beberapa faktor misalnya jumlah konidium dan adanya luka yang membantu atau menghambat perkembangan patogen yang mempengaruhi lamanya periode inkubasi. Faktor tersebut tidak sama antara satu isolat dengan isolat yang lain. Isolat yang digunakan dalam penelitian mempunyai tingkat adaptasi terhadap lingkungan yang berbeda sehingga menunjukkan masa inkubasi yang berbeda pula. Lamanya periode inkubasi biasanya ditentukan oleh kekhususan gabungan antara patogen, tanaman inang, dan lingkungan (Winarni, 2004).

Perbedaan lama masa inkubasi juga terjadi akibat penyimpanan isolat dalam medium tanah steril dalam waktu yang cukup lama sehingga memengaruhi kemampuan dari masing-masing isolat dalam menimbulkan penyakit. Sesuai dengan pendapat Agrios (1988) yang menyatakan bahwa kehilangan virulensi dalam biakan atau pada inang lebih merupakan akibat dari seleksi individu dari strain patogen yang kurang virulen. Virulensi patogen dapat hilang sama sekali walaupun masih mampu untuk memperbanyak diri dalam medium biakan apabila isolat patogen tersebut mengalami beberapa kali pemindahan medium biakan atau pada inang lain. Selain itu, perbedaan tingkat virulensi isolat jamur F. oxysporum f.sp. zingiberi menunjukkan adanya

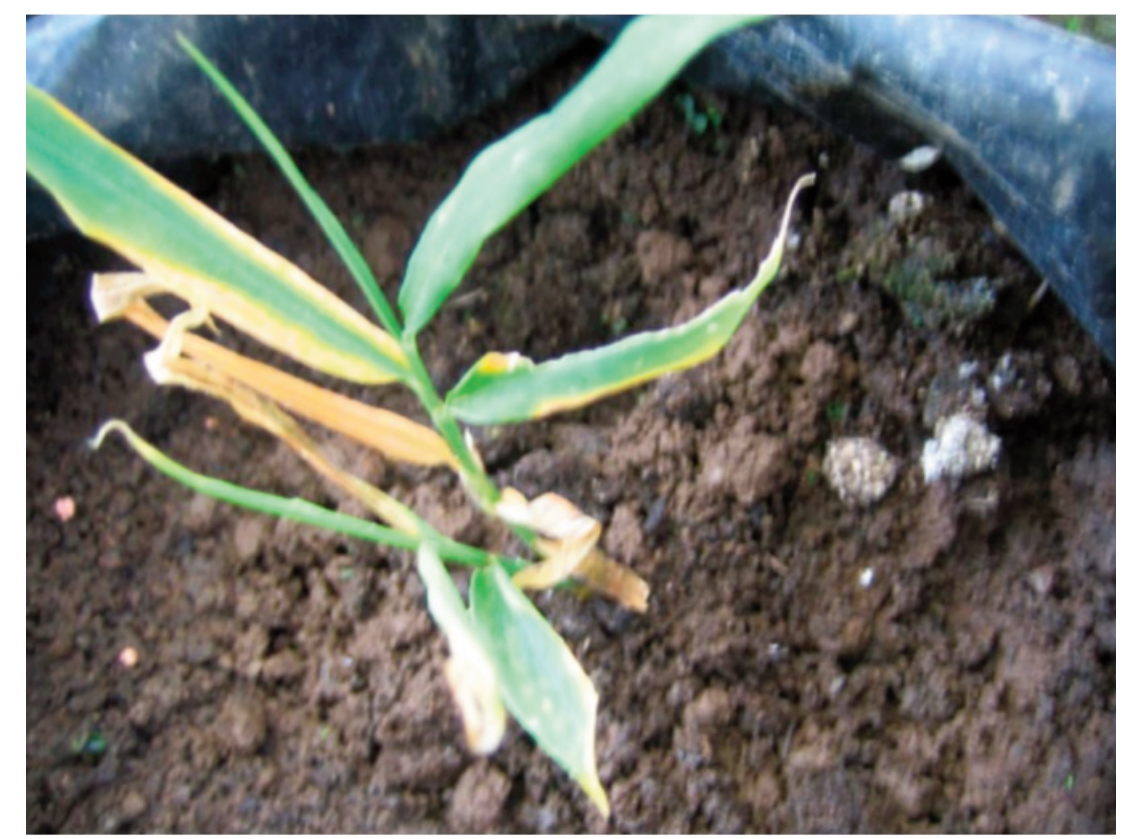

Gambar 2. Gejala serangan Fusarium oxysporum f.sp.zingiberi pada tanaman jahe gajah berupa menguningnya bagian tepi ujung daun, terutama daun sebelah bawah dan kemudian daun akan mengering 
keragaman jamur patogen meskipun berasal dari forma spesialis yang sama (Sastrahidayat, 1990).

Tanaman jahe yang terserang menunjukkan gejala menguningnya bagian tepi ujung daun, terutama daun sebelah bawah kemudian daun akan mengering (Gambar 2). Penguningan daun kadang terjadi pada setengah sisi dari helaian daun, gejala berlanjut secara terus menerus pada daun yang lebih muda di atasnya. Tanaman secara keseluruhan dapat menjadi kerdil. Apabila rimpang sudah busuk, maka batang tanaman menjadi layu dan akhirnya rebah dan mati. Hal ini sesuai dengan pernyataan Semangun (2000) bahwa gejala awal penyakit Fusarium sp. ditandai dengan daun bawah menguning, menjadi layu, pucuk tanaman mengering dan lama-kelamaan mati, terkadang tanaman juga mengalami kekerdilan.

Gejala yang nampak dari masing-masing perlakuan tidak sama. Perbedaan ini disebabkan masa inkubasi dari masing-masing perlakuan juga berbeda. Semakin cepat masa inkubasi maka gejala yang ditimbulkan akan semakin berat begitu juga sebaliknya.

\section{Intensitas Penyakit Busuk Rimpang Jahe}

Hasil analisis statistika terhadap intensitas penyakit busuk rimpang jahe tidak menunjukkan ada perbedaan pada masing-masing perlakuan. Walaupun demikian terdapat perbedaan besaran nilai intensitas penyakit di antara perlakuan yang dicoba. Rerata tertinggi ditunjukkan oleh isolat MSO1 dan terendah ditunjukkan oleh isolat SAO1 sebesar (Tabel 2).

Hadi et al. (1975) cit. Rosnawati (1991) menyatakan bahwa tingginya intensitas penyakit dipengaruhi oleh masa inkubasi, kepadatan konidium, dan kemampuan patogen menyerang berkas pembuluh pada tanaman jahe erat hubungannya dengan pengangkutan air dalam tanaman karena Fusarium berada di dalam pembuluh xilem dan konidiumnya terangkut dalam aliran transpirasi. Cepat lambatnya pengangkutan tersebut juga memengaruhi cepat lambatnya kelayuan. Semua isolat yang dicoba kemungkinan mempunyai kemampuan yang tidak berbeda dalam menyebabkan penyakit pada tanaman jahe.

\section{Pertumbuhan Tanaman}

Salah satu ukuran pertumbuhan suatu tanaman adalah tinggi tanaman dan jumlah daun. Menurut Sitompul dan Guritno (1995), tinggi tanaman merupakan ukuran tanaman yang sering diamati sebagai parameter yang digunakan untuk mengukur pengaruh lingkungan atau perlakuan yang diterapkan. Tidak terdapat perbedaan pada tinggi tanaman dan jumlah daun yang diamati. Rerata tinggi tanaman dan jumlah daun terbesar ditunjukkan oleh perlakuan isolat MBM. Sedangkan tinggi tanaman dan jumlah daun terendah ditunjukkan oleh perlakuan isolat SAO6 (Tabel 2).

Patogen dapat menimbulkan dampak terhadap fungsi fisiologi tumbuhan seperti fotosintesis, translokasi air dan zat hara dalam jaringan inangnya. Patogen penyebab layu dapat menimbulkan permukaan daun layu kemudian menguning sehingga mengganggu proses fotosintesis. Penyakit layu yang diakibatkan jamur Fusarium sp. dapat mengganggu pengambilan air dan senyawa organik dari tanah. Seperti yang telah diketahui bahwa $F$. oxysporum merupakan patogen yang menyerang pembuluh xilem yang merupakan jaringan pengangkutan air dan unsur hara dari akar ke daun dan seluruh tubuh tanaman. Karena infeksi patogen tersebut, maka akan terjadi penyumbatan di dalam pembuluh xilem sehingga aliran translokasi hara dan air dalam tanaman terhambat (Pancasiwi, 2004).

\section{DAFTAR PUSTAKA}

Agrios, G. N. 1988. Ilmu Penyakit Tumbuhan, edisi ketiga. (Diterjemahkan oleh B. Munsir). Gadjah Mada University Press, Yogyakarta. $713 \mathrm{hlm}$.

Amalia, R. 2004. Potensi Beberapa Antagonis dalam Menekan F. oxysporum $f$. sp. zingiberi Trujillo In vitro dan In planta pada Tanaman Jahe. Skripsi. Fakultas Pertanian, Universitas Jenderal Soedirman, Purwokerto. 56 hlm. (tidak dipublikasikan).

Anonim. 2010. Produksi Tanaman Obat. http://www. Hortikultura.go.id/horti/page/statistik/lppobat.asp, diakses 28/7/08.

Pancasiwi, D. 2004. Uji Ketahanan Beberapa Varietas Jahe terhadap Fusarium oxysporum $f$. $s p$. zingiberi secara In vitro dan In planta. Skripsi. Fakultas Pertanian, Universitas Jenderal Soedirman, Purwokerto. 43 hlm. (tidak dipublikasikan).

Riyadi, A.S., L. Soesanto, \& Kustantinah. 2008. Virulensi Fusarium oxysporum f.sp. zingiberi Isolat Boyolali dan Temanggung Setelah Disimpan Enam Tahun dalam Tanah Steril. Jurnal Perlindungan Tanaman Indonesia 14: 80 - 85 .

Rosnawati, E. 1991. Uji Resistensi Beberapa Varietas Cabai terhadap Penyakit Layu oleh Jamur. Skripsi. Universitas Jenderal Soedirman, Purwokerto. 63 hlm. (tidak dipublikasikan).

Rukmana, R. 2000. Usaha Tani Jahe. Kanisius, Yogyakarta. $64 \mathrm{hlm}$. 
Sastrahidayat, I.R. 1990. Ilmu Penyakit Tumbuhan. Usaha Nasional, Surabaya. $366 \mathrm{hlm}$.

Semangun, H. 2000. Penyakit-Penyakit Tanaman Hortikultura di Indonesia. Gadjah Mada University Press, Yogyakarta. $849 \mathrm{hlm}$.

Sitompul, S. M. \& B. Guritno. 1995. Analisis Pertumbuhan Tanaman. Gadjah Mada University Press, Yogyakarta. 411 hlm.

Soesanto, L. 2006. Fusarium Utama pada Tanaman Pangan: Cara Pengendaliannya dan Teknik Penyimpanan Konidiumnya. Makalah disampaikan pada Seminar Nasional II dan Workshop Fusarium, Padang, 14-16 Agustus 2006.
Soesanto, L., Soedarmono, N. Prihatiningsih, A. Manan, E. Iriani, \& J. Pramono. 2002. Kajian Geofitopatologis Penyakit Busuk Rimpang Tanaman Jahe di Wilayah Jawa Tengah. Laporan Kegiatan. Lembaga Penelitian Universitas Jenderal Soedirman, Purwokerto dan BPTP Jateng, Ungaran. $47 \mathrm{hlm}$.

Tombe, M.E. Taufik, Supriadi, \& D. Sitepu. 1997. Penyakit Busuk Akar Rimpang Fusarium pada Bibit Jambu Mente. hlm 183-190. Forum Konsultasi Ilmiah Perbenihan Tanaman Rempah dan Obat, 13-14 Maret 1997, Bogor.

Winarni, W. 2004. Uji Patogenisitas Beberapa Isolat Fusarium oxysporum $f . s p$. zingiberi pada Tanaman Jahe Gajah. Skripsi. Fakultas Pertanian. Universitas Jenderal Soedirman, Purwokerto. 33 hlm. (tidak dipublikasikan). 